\title{
Right atrial isomerism in children older than 3 years
}

\author{
Sun Yan ${ }^{\dagger}$, Wang Jianpeng ${ }^{\dagger}$, Quan Xin, Zhang Minghui, Zhang Li and Wang Hao*
}

\begin{abstract}
Background: There is a high mortality in infants with right atrial isomerism (RAl). However, less is known about outcome in older children with RAI. This study sought to evaluate those patients with RAI who survived older than 3 years of age without surgical intervention.

Results: A total of 33 consecutive patients (20 males) were enrolled in the study, mean age 6 years (range 3-32). None of the patients had surgical intervention for the RAl before age 3. Cardiac abnormalities include altered cardiac position (39\%), atrioventricular valve anomaly ( $87 \%$ ), single or functional single ventricle (55\%), pulmonary/subpulmonary obstruction (97\%), abnormal origin of the aorta (100\%), bilateral superior vena cava (67\%), and anomalous pulmonary venous drainage (66\%). Surgical intervention was performed after 3 years of age in 20 patients (61\%). None of them planned or had biventricular repair performed. 10 patients underwent the total cavopulmonary connection procedure, including four (40\%) who had atrioventricular valve (AVV) repair at the same time [all with common atrioventricular valve (CAVV)]. One patient died the day after the operation. A total of $69 \%$ of patients with a CAVV had moderate or severe regurgitation, while $27 \%$ with a single atrioventricular valve had moderate or severe regurgitation.
\end{abstract}

Conclusion: Patients with RAI who have survived to early childhood without surgical intervention have complex cardiac abnormalities. Survival after single stage total cavopulmonary connection is good but AVV repair is common.

\section{Background}

Congenital heart disease (CHD) affects $0.75-0.9 \%$ of newborns and is a leading cause of infant mortality (Van der Linde et al. 2011; Hoffman and Kaplan 2002). With major improvements in medical and surgical treatment of CHD in recent years, more than $90 \%$ of patients with CHD survive into adulthood (Khairy et al. 2010; Marelli et al. 2007). However, heterotaxy syndrome is one of the most serious forms of $\mathrm{CHD}$, occurring in approximately 1 in 5000-7000 live births with CHD (Reller et al. 2008; Lin et al. 2000).

The International Nomenclature Committee for Pediatric and Congenital Heart Disease defines heterotaxy syndrome as an abnormality where the

\footnotetext{
*Correspondence: sunxiaoyan01@sina.com

† Sun Yan and Wang Jianpeng contributed equally to this work Department of Echocardiography, Fuwai Hospital, Chinese Academy of Medical Sciences, Peking Union Medical College, No. 167, Bei Li Shi Road, Xicheng District, Beijing 100037, China
}

internal thoraco-abdominal organs demonstrate abnormal arrangement across the left-right axis of the body (Jacobs et al. 2007). Patients with heterotaxy syndrome are subdivided into right atrial isomerism (RAI) and left atrial isomerism (LAI) (Cohen et al. 2007). RAI is typically associated with complex cardiovascular malformations (Freedom et al. 2005; Eronen et al. 2013), with overall 5-year survival rates ranging from 30 to $74 \%$ (Sinzobahamvya et al. 1999; Culbertson et al. 1992). RAI has a particularly high mortality rate in infants. To our knowledge, there are no previous reports on older RAI patients who have not had surgery with regard to survival and how their cardiac condition differs from infants with RAI.

Diagnosis of RAI remains a challenge. Patients with RAI have abnormalities in the lungs and various intraabdominal organs, and each side of the heart morphologically resembles the right atrium and right atrial appendages. Most affected patients also have juxtaposition of the abdominal aorta and asplenia. Radiological 
diagnosis of RAI may be suspected on plain radiographic films of the chest and abdomen, by identifying the position of the liver and stomach, and bronchial pattern (Freedom and Fellow 1973). Echocardiographic or angiographic demonstration of a juxtaposition of the aorta and inferior vena cava, and morphology of the atrial appendages are used to support the diagnosis (Huhta et al. 1982).

This study aimed to investigate the natural history of patients with RAI whose surgical correction did not occur until after 3 years old. We also sought to assess their surgical outcomes when late palliation was performed.

\section{Methods}

\section{Definitions and identification of patients}

We performed a retrospective study of all patients who were diagnosed between October 2010 and February 2014 with RAI in our pediatric center and were older than 3 years without prior surgical correction. A total of 33 consecutive patients ( 20 males, 13 females) were identified with a median age of 6 years (range: 3-32 years). Diagnosis of RAI was confirmed at surgery, when bilateral right atrial morphology was found. All patients were Asian. The study protocol was approved by local research and ethical review boards.

Information on all of the patients' cardiac lesions was collected, including anomalous heart position, common atrium, major atrioventricular (AV) valve anomaly, pulmonary outflow obstruction, anomalous pulmonary venous connections, obstruction of pulmonary venous connections, and systemic outflow obstruction. Data on age at the first surgical intervention and types of interventions were also collected. Early mortality was defined as death occurring at any time before hospital discharge or within 30 days after the operation (even if the patient had been discharged). The day of operation was considered as day 1 for calculating the length of hospital stay. The hospital stay was considered "prolonged" after 21 days.

\section{Data analysis}

Demographic and anatomic data, as well as procedural and outcome frequencies, were analyzed and results are presented as the number (\%) of patients. Univariate analysis of the association of variables with mortality was performed using the Chi square test. A probability value of $p<0.05$ was considered significant.

\section{Results}

\section{Cardiac morphology}

An abnormal heart location was observed in 13 (40 \%) patients, including dextrocardia and mesocardia. Septal defects occurred in all 33 (100\%) patients, including single atrium, single ventricle, and atrioventricular septal defect. Only one patient lacked an atrial septal defect, but this patient had a large ventricular defect $(>10 \mathrm{~mm}$ in diameter). All of the patients in this study had ventricular septal defects. Only one patient had a ventricular defect smaller than $10 \mathrm{~mm}$; however, this patient also had a uniatrium. Atrioventricular valve (AVV) abnormalities occurred in 27 (87\%) patients, including a common atrioventricular valve (CAVV) and a single atrioventricular valve (SAVV) (morphologically tricuspid valve). The ventriculoarterial connection was abnormal in all 33 (100\%) patients, with the aorta originating abnormally from a univentricle, from the right ventricle, or overriding. Twenty-four (72\%) patients had a double outlet right ventricle.

Thirty-one (97\%) patients had pulmonary and (or) subpulmonary obstruction, including right ventricle outlet stenosis (57\%), pulmonary artery valve stenosis (8\%), or pulmonary atresia (9\%). Anomalous pulmonary venous drainage was observed in 21 (63\%) patients, including total anomalous pulmonary venous connection (TAPVC) and partially anomalous pulmonary venous connection (PAPVC). The incidence of these abnormalities is shown in Table 1.

\section{Pulmonary venous drainage}

In our study, 15 (45\%) patients had TAPVD, while six (18\%) had PAPVD. Pulmonary veins were observed in a variety of abnormal configurations, including connection to the right side of the atrium, to both sides of the atrium separately, to the right superior vena cava, to the left superior vena cava, to the right atrium and left superior vena cava combined, and to the left atrium and left superior vena cava combined. The incidence of these abnormalities is shown in Table 2.

\section{Atrioventricular valve morphology and function}

Twenty-seven (87\%) patients had an AVV anomaly. Sixteen $(52 \%)$ patients had CAVV and a single AV valve was observed in 11 (35\%) patients, including a morphologically tricuspid valve in $10(91 \%)$ patients and a morphologically mitral valve in one $(9 \%)$ patients. Echocardiography was used to estimate AV regurgitation for CAVV and SAVV cases. Table 3 shows characterization of AV regurgitation with CAVV and SAVV.

\section{Surgical interventions}

Cardiovascular surgical interventions were performed in $20(61 \%)$ patients. Two of these $(10 \%)$ underwent a modified Blalock-Taussig shunt, including one patient who had systemic-to-pulmonary collateral coiling performed at the same time. Seven (35\%) patients underwent a bidirectional Glenn shunt, including six (30 \%) 
Table 1 Anatomic cardiac findings among RAI patients

\begin{tabular}{|c|c|c|}
\hline & No. of patients & Percent (\%) \\
\hline Cardiac position abnormal & 13 & 39 \\
\hline Dextrocardia & 12 & 36 \\
\hline Mesocardia & 1 & 3 \\
\hline Atrioventricular septal anomaly & 33 & 100 \\
\hline Atrium septum defect & 32 & 97 \\
\hline $\begin{array}{l}\text { Single atrium or functionally single } \\
\text { atrium }\end{array}$ & 20 & 61 \\
\hline Ventricle septum defect & 33 & 100 \\
\hline $\begin{array}{l}\text { Single ventricle or functionally single } \\
\text { ventricle }\end{array}$ & 19 & 58 \\
\hline Atrioventricular valve anomaly & $27 / 31$ & 87 \\
\hline SAVV (morphologically tricuspid valve) & $10 / 31$ & 32 \\
\hline SAVV (morphologically mitral valve) & $1 / 31$ & 3 \\
\hline CAVV & $6 / 31$ & 51 \\
\hline Aorta origin abnormal & 33 & 100 \\
\hline From univentricle & 15 & 45.5 \\
\hline From right ventricle & 17 & 51.5 \\
\hline Overriding & 1 & 3 \\
\hline Great arteries location abnormal & 26 & 78 \\
\hline Aorta located on left of pulmonary & 2 & 6 \\
\hline Right anterior & 10 & 30 \\
\hline Right & 4 & 12 \\
\hline Right posterior & 1 & 2 \\
\hline Antterior & 7 & 21 \\
\hline Pulmonary atresia & 3 & 9 \\
\hline $\begin{array}{l}\text { Pulmonary and (or) subpulmonary } \\
\text { stenosis }\end{array}$ & 32 & 97 \\
\hline Subpulmonary stenosis & 19 & 57 \\
\hline Pulmonary stenosis & 28 & 84 \\
\hline Pulmonary atresia & 3 & 9 \\
\hline $\begin{array}{l}\text { Anomalous common pulmonary venous } \\
\text { trunk (ACPVT) }\end{array}$ & 17 & 51 \\
\hline $\begin{array}{l}\text { Anomalous pulmonary venous connec- } \\
\text { tion }\end{array}$ & 21 & 63 \\
\hline PAPVC & 6 & 18 \\
\hline TAPVC & 15 & 45.5 \\
\hline BSVC & 22 & 67 \\
\hline
\end{tabular}

SAVV single atrioventricular valve, CAVV common atrioventricular valve, PAPVC partially anomalous pulmonary venous connection, TAPVC total anomalous pulmonary venous connection, $B S V C$ bilateral superior vena cava

who received a bilateral bidirectional Glenn shunt. Of these six patients, one received concurrent patent ductus arteriosus (PDA) ligation and pulmonary artery widening, and one underwent TAPVC repair.

Ten $(50 \%)$ patients had the total cavopulmonary connection (TCPC) procedure, including four (40\%) who underwent AVV repair at the same time. One patient had a bilateral bidirectional Glenn shunt followed by a successful TCPC procedure. No patients had biventricular
Table 2 Pulmonary venous drainage

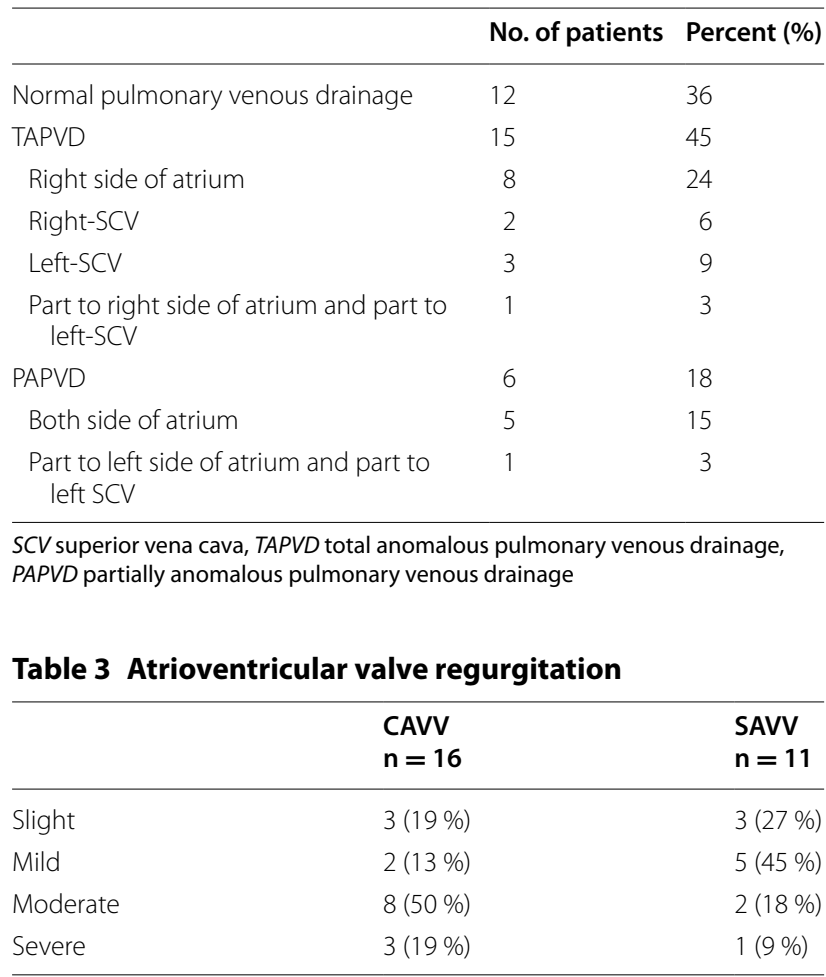

CAVV common atrioventricular valve, SAVV single atrioventricular valve

repair or were prepared to have biventricular repair. The median duration of hospitalization among patients who underwent the TCPC procedure was 21 days (range: 15-90 days), with a median duration of intubation of 2 days (range: $1-8$ days). Three (27 \%) patients who received the TCPC procedure had prolonged hospital stay ( $>21$ days). Reoperation during the hospital period was necessary in three $(15 \%)$ patients; two of these patients underwent TCPC and the other patient received a bilateral bidirectional Glenn shunt and PDA ligation. Only one patient died the day after operation; this patient also had a reoperation.

Of the six patients who received only TCPC, five (83 \%) had an SAAV (morphologically tricuspid valve) and the other had a CAVV and died the next day after the operation. All four of the patients who underwent concurrent TCPC and AVV repair had CAVV. The patients' degree of pre-surgical AVV regurgitation is shown in Table 4.

Surgical intervention was not performed in 13 (39\%) patients, with pulmonary hypertension in four (one case without pulmonary and/or subpulmonary stenosis, three cases with mild pulmonary valve stenosis), hypoplasia of the pulmonary artery in three, and moderate or severe regurgitation of the AVV in three patients. 
Table 4 Atrioventricular valve structure and function in TCPC patients with or without valve repair

\begin{tabular}{lll}
\hline & TCPC $(\mathbf{n}=\mathbf{6})$ & TCPC + AVR $(\mathbf{n = 4})$ \\
\hline $\begin{array}{ll}\text { Morphology of AV valve } \\
\text { SAVV (morphologically } \\
\text { tricuspid valve) }\end{array}$ & $5(83 \%)$ & 0 \\
CAAV & $1(17 \%)$ early death & $4(100 \%)$ \\
$\begin{array}{ll}\text { Degree of AV valve regurgitation } \\
\text { Slight }\end{array}$ & $3(50 \%)$ & 0 \\
Mild & $3(50 \%)$ & 0 \\
Moderate & 0 & $2(50 \%)$ \\
Severe & 0 & $2(50 \%)$ \\
Early mortality & 1 & 0
\end{tabular}

TCPC total cavopulmonary connection, AVR atrioventricular valve repair, $A V$ atrioventricular, CAVV common atrioventricular valve, SAVV single atrioventricular valve

\section{Comparison with previous study}

Table 5 shows comparison of our study results with a previous report (Cheung et al. 2002), which discussed common abnormalities of patients with RAI. In the previous report, $89 \%$ of patients presented during the 1 st month of life. Therefore, this report described the initial abnormalities of patients with RAI. Our report described abnormalities of RAI patients who survived for at least 3 years without surgery. We found that the percentages of patients with CAVV, pulmonary vein obstruction,

Table 5 Comparison of anatomic cardiac findings and outcome with previous reports

\begin{tabular}{|c|c|c|}
\hline & $\begin{array}{l}\text { This report } \\
(\mathrm{n}=33)\end{array}$ & $\begin{array}{l}\text { Cheung et al. } \\
(n=116)\end{array}$ \\
\hline The time of presented RAl & More than 3 year old & $76 \%$ Within first week \\
\hline Male & $20(61 \%)$ & 71/116 (61 \%) \\
\hline Levocardia & $20(61 \%)$ & $81 / 116(70 \%)$ \\
\hline Dextrocardia/mesocardia & $13(39 \%)$ & $35 / 116(30 \%)$ \\
\hline $\begin{array}{l}\text { Single or functionally } \\
\text { single atrium }\end{array}$ & $20(61 \%)$ & $69(59 \%)$ \\
\hline $\begin{array}{l}\text { Single or functionally } \\
\text { single ventricle }\end{array}$ & $19(58 \%)$ & $96(83 \%)^{* *}$ \\
\hline $\begin{array}{l}\text { Pulmonary/subpulmonary } \\
\text { obstruction }\end{array}$ & $33(100 \%)$ & $96(83 \%)$ \\
\hline Pulmonary atresia & $3(9 \%)$ & $48(41 \%)^{* *}$ \\
\hline CAVV & $16 / 31(51 \%)$ & $107(92 \%)^{* *}$ \\
\hline $\begin{array}{l}\text { Pulmonary vein obstruc- } \\
\text { tion }\end{array}$ & 0 & $15(13 \%)^{*}$ \\
\hline APVD & $21(63 \%)$ & $60(52 \%)$ \\
\hline $\begin{array}{l}\text { Systemic outflow obstruc- } \\
\text { tion }\end{array}$ & 0 & $4(3 \%)$ \\
\hline
\end{tabular}

CAVV common atrioventricular valve, BSVC bilateral superior vena cava, $A P V D$ anomalous pulmonary venous drainage, pulmonary atresia $(p=0.05)$; * $p<0.05$; ${ }^{* *} p<0.01$ single or functional single ventricle, and pulmonary atresia were significantly different between the previous study and our study. There were no significant differences in the percentages of patients who were male and those who demonstrated dextrocardia/mesocardia, pulmonary/subpulmonary obstruction, or a single or functional single atrium between studies.

\section{Discussion}

To the best of our knowledge, this is the only report in English of a clinical series cataloging the various cardiac lesions and outcomes of patients with RAI who received surgical treatment older than 3 years of age. Despite late diagnosis, many of these patients survive surgical palliation.

\section{Cardiac lesions}

Anomalous pulmonary venous drainage

In our study, $15(45 \%)$ patients had TAPVC and six (18 \%) had PAPVC. These results are consistent with previous studies (Eronen et al. 2013; Cheung et al. 2002). Sadiq et al. (1996) reported an overall survival rate of $18 \%$ in patients requiring surgery in the 1 st month of life and $78 \%$ in patients requiring surgery after the 1 st month of life. RAI is always combined with the presence of a single atrium and/or single ventricle. Therefore, patients with RAI with APVC do not need an emergent operation unless they have an obstructed anomalous pulmonary venous connection or other factors. This explains why there was no significant difference in the rate of anomalous pulmonary venous drainage between our study and the previous study.

\section{Pulmonary/subpulmonary obstruction}

Pulmonary atresia was observed in three (9\%) patients, pulmonary stenosis in $28(87 \%)$ patients, and a normal pulmonary artery and pulmonary valve in two (6\%) patients. One patient with a normal pulmonary artery and pulmonary valve had right ventricular outflow stenosis. Patients with pulmonary/subpulmonary obstruction do have higher survival rates. Hashmi et al. (1998) reported that the absence of pulmonary outflow obstruction was an independent risk factor for earlier death. Previous studies have shown that $8-15 \%$ of patients with RAI need pulmonary artery banding (PAB), and mortality of these patients with PAB is 75-95 \% (Eronen et al. 2013; Cheung et al. 2002; Ota et al. 2012). This could explain why few patients with pulmonary atresia were observed in our study. In our study, there was one patient without pulmonary and subpulmonary obstruction. This patient and three other patients with mild pulmonary stenosis lost the opportunity for surgical interventions. 


\section{Obstructed anomalous pulmonary venous connection}

Previous studies have indicated that $25-45 \%$ of patients with RAI also have an obstructed anomalous pulmonary venous connection (Cheung et al. 2002; Sadiq et al. 1996; Yun et al. 2006). In our study, however, no patients had an obstructed anomalous pulmonary venous connection. An obstructed anomalous pulmonary venous connections is a poor prognostic indicator in RAI (Sadiq et al. 1996; Phoon and Neill 1994). The surgical mortality rate in patients with pulmonary vein repair is $95-97 \%$ and it is thought to be an independent risk factor for early death (Jenkins et al. 1993). Patients with an obstructed anomalous pulmonary venous connection are unlikely to survive beyond 3 years of age. Therefore, this could explain the significant difference in the number of patients with an obstructed anomalous pulmonary venous connection in our study compared with previous studies. Our study further confirms the risk of RAI with obstructed anomalous pulmonary venous connection.

\section{Atrioventricular valve morphology and function}

AVV morphology and function are important factors when considering surgery. In our study, although the total proportion of patients with an abnormal AVV was similar to that in previous studies (Cheung et al. 2002), the proportion of CAVV was significantly lower. Previous studies (Cheung et al. 2002) have shown that the incidence of CAVV in RAI is $75-100 \%$. In our study, we found that all patients undergoing TCPC and AVV repair had a CAVV. All of the patients undergoing TCPC without AVV repair had an SAVV, except for one patient who died soon after the operation. This finding suggests that CAVV was likely associated with moderate or severe regurgitation, leading to earlier AVV repair.

AVV regurgitation in RAI is primarily caused by structural abnormalities, including abnormal clefts and commissures, dysplastic leaflets, and elongated or shortened chordae (Uemura et al. 1998; Kawahira et al. 1997). Ota et al. (2012) reported that $13(21.7 \%)$ patients with RAI had severe systemic AVV regurgitation on their first echocardiogram. Perioperative management with intubation and nitrogen inhalation reduced the AVV regurgitation in five $(8 \%)$ of these patients, and the remaining eight (13\%) patients underwent valve repair at their initial palliative operation. Persistent AVV regurgitation, which is regurgitation that persists or recurs after attempted valve repair, is a potential risk factor for mortality (Hashmi et al. 1998). The peculiar morphological characteristics of the AVV may be the cause of frequent valvar regurgitation in patients with RAI (Francalanci et al. 1996; Lin et al. 2002). AVV regurgitation leads to an enlarged ventricle and atrioventricular annulus, further increasing atrioventricular regurgitation with age. This could explain why a high number of patients required AVV repair in our study. In our study, we observed that CAVV regurgitation was more problematic than SAVV.

\section{Bilateral superior vena cava}

In our study, 22 (67\%) patients had bilateral superior vena cava. This rate is much higher than that observed in a previous study (26\%) (Ota et al. 2012). The reason for this difference in findings is unclear. No previous studies have demonstrated that a single superior vena cava is a risk factor for early death. We suspect that pulmonary venous drainage obstruction is more likely in patients with only one superior vena cava than in patients with bilateral superior vena cavas. Therefore, the presence of bilateral superior vena cava may reduce obstruction of pulmonary venous drainage.

\section{Systemic outflow stenosis}

Previous studies have shown an incidence of 5-12\% of systemic outflow stenosis in patients with RAI (Eronen et al. 2013; Ota et al. 2012; Kawahira et al. 1997). Systemic outflow stenosis may increases the difficulty of the operation. And the infant mortality rate within this group is nearly $100 \%$ (Ota et al. 2012). This could explain why patients with systemic outflow obstruction were not found in our study.

\section{Study limitations}

Our institution, Fuwai Hospital,is a specialty institution with Pediatric Cardiac Surgical Center for congenital cardiac patients. However, we do not have newborn service in this hospital. Therefore, no prenatal or neonatal patients were enrolled into this study. This made it difficult to determine some risk factors for a poor outcome in patients with RAI. Several genes are responsible for leftright laterality and heterotaxy syndrome, including ZIC3, NODAL, and LEFTY2 (Belmont et al. 2004; Zhu et al. 2006). Despite high infant mortality rates, some patients with RAI can live to at least 3 years of age without surgery. We suspect that genetic differences may lead to this anatomy, but we did not perform any genetic analysis in our study.

\section{Conclusion}

Our study reports that some RAI patients can survive beyond 3 years of age without surgical intervention despite having complex cardiac abnormalities. In older RAI patients, survival after single stage total cavopulmonary connection is good. CAVV regurgitation is more serious than SAVV regurgitation and it frequently needs to be repaired. Further studies, especially genetic studies, are warranted to improve the long-time results for these older patients. 


\section{Authors' contributions}

Study conception and design: SY, WH, and WJP. Collection and assembly of data: SY, ZMH, and ZL. Data analysis: SY, WH, WJP, and QX. Manuscript writing and final approval: SY, QX, WH, and WJP. All authors read and approved the final manuscript.

\section{Acknowledgements}

The authors wish to acknowledge the contribution of Yan Jun (Pediatric Center of Cardiac Surgery Cardiovascular) for instruction in surgery.

\section{Competing interests}

The authors declare that they have no competing interests.

Received: 22 October 2015 Accepted: 5 August 2016

Published online: 20 August 2016

\section{References}

Belmont JW, Mohapatra B, Towbin JA, Ware SM (2004) Molecular geneticsof heterotaxy syndromes. Curr Opin Cardiol 19(3):216-220

Cheung YF, Cheng VY, Chau AK, Chiu CS, Yung TC, Leung MP (2002) Outcome of infants with right atrial isomerism: is prognosis better with normal pulmonary venous drainage? Heart 87(2):146-152

Cohen MS, Anderson RH, Cohen MI, Atz AM, Fogel M, Gruber PJ et al (2007) Controversies, genetics, diagnostic assessment, and outcomes relating to the heterotaxy syndrome. Cardiol Young 17(Suppl 2):29-43

Culbertson DB, George Bl, Day RW, Laks H, Williams RG (1992) Factors influencing survival of patients with heterotaxy syndrome undergoing Fontan procedure. J Am Coll Cardiol 20(3):678-684

Eronen MP, Aittomäki KA, Kajantie EO, Sairanen HI, Pesonen EJ (2013) The outcome of patients with right atrial isomerism is poor. Pediatr Cardiol 34(2):302-307

Francalanci P, Marino B, Boldrini R, Abella R, lorio F, Bosman C (1996) Morphology of the atrioventricular valve in asplenia syndrome: a peculiar type of atrioventricular canal defect. Cardiovasc Pathol 5(3):145-151

Freedom RM, Fellow KE Jr (1973) Radiographic visceral patterns in the asplenia syndrome. Radiology 107(2):387-391

Freedom RM, Jaeggi ET, Lim JS, Anderson RH (2005) Hearts with isomerism of the right atrial appendages-one of the worst forms of disease in 2005 Cardiol Young 15(6):554-567

Hashmi A, Abu-Sulaiman R, McCrindle BW, Smallhorn JF, Williams WG, Freedom RM (1998) Management and outcomes of right atrial isomerism: a 26-year experience. J Am Coll Cardiol 31(5):1120-1126

Hoffman Jl, Kaplan S (2002) The incidence of congenital heart disease. J Am Coll Cardiol 39(12):1890-1900

Huhta JC, Smallhorn JF, Macartney FJ (1982) Two dimensional echocardiographic diagnosis of situs. Br Heart J 48(2):97-108

Jacobs JP, Anderson RH, Weinberg PM, Walters HL 3rd, Tchervenkov Cl, Del Duca D, Franklin RC, Aiello VD, Béland MJ, Colan SD, Gaynor JW,
Krogmann ON, Kurosawa H, Maruszewski B, Stellin G, Elliott MJ (2007) The nomenclature, definition and classification of cardiac structures in the setting of heterotaxy. Cardiol Young 17(Suppl 2):1-28

Jenkins KJ, Sanders SP, Orav EJ, Coleman EA, Mayer JE, Colan SD (1993) Individual pulmonary vein size and survival in infants with totally anomalous pulmonary venous connection. J Am Coll Cardiol 22(1):201-206

Kawahira Y, Kishimoto H, Kawata H, Ikawa S, Ueda H, Nakajima T, Kayatan F, Inamura N, Nakada T (1997) Morphologic analysis of common atrioventricular valves in patients with right atrial isomerism. Pediatr Cardiol 18(2):107-111

Khairy P, Ionescu-Ittu R, Mackie AS, Abrahamowicz M, Pilote L, Marelli AJ (2010) Changing mortality in congenital heart disease. J Am Coll Cardiol 56(14):1149-1157

Lin AE, Ticho BS, Houde K, Westgate MN, Holmes LB (2000) Heterotaxy: associated conditions and hospital-based prevalence in newborns. Genet Med 2(3):157-172

Lin JH, Chang Cl, Wang JK, Wu MH, Shyu MK, Lee CN, Lue HC, Hsieh FC (2002) Intrauterine diagnosis of heterotaxy syndrome. Am Heart J 143(6):1002-1008

Marelli AJ, Mackie AS, Ionescu-Ittu R, Rahme E, Pilote L (2007) Congenital heart disease in the general population: changing prevalence and age distribution. Circulation 115(2):163-172

Ota N, Fujimoto Y, Murata M, Tosaka Y, Ide Y, Tachi M, Ito H, Sugimoto A, Sakamoto K (2012) Improving outcomes of the surgical management of right atrial isomerism. Ann Thorac Surg 93(3):832-838

Phoon CK, Neill CA (1994) Asplenia syndrome-risk factors for early unfavorable outcome. Am J Cardiol 73(16):1235-1237

Reller MD, Strickland MJ, Riehle-Colarusso T, Mahle WT, Correa A (2008) Prevalence of congenital heart defects in metropolitan Atlanta, 1998-2005. J Pediatr 153(6):807-813

Sadiq M, Stümper O, De Giovanni JV, Wright JG, Sethia B, Brawn WJ, Silove ED (1996) Management and outcome of infants and children with right atrial isomerism. Heart 75(3):314-319

Sinzobahamvya N, Arenz C, Brecher AM, Urban AE, Sinzobahamvya N, Arenz C, Brecher AM et al (1999) Atrial isomerism: a surgical experience. Cardiovasc Surg 7:436-442

Uemura H, Ho SY, Anderson RH, Yagihara T (1998) The structure of the common atrioventricular valve in hearts having isomeric atrial appendages and double inlet ventricle. J Heart Valve Dis 7(5):580-585

Van der Linde D, Konings EE, Slager MA, Witsenburg M, Helbing WA, Takkenberg JJ, Roos-Hesselink JW (2011) Birth prevalence of congenital heart disease worldwide: a systematic review and meta-analysis. J Am Coll Cardiol 58(21):2241-2247

Yun TJ, Al-Radi OO, Adatia I, Caldarone CA, Coles JG, Williams WG, Smallhorn J, Van Arsdell GS (2006) Contemporary anagement of right atrial isomerism: effect of evolving therapeutic strategies. JThorac Cardiovasc Surg 131(5):1108-1113

Zhu L, Belmont JW, Ware SM (2006) Genetics of human heterotaxias. Eur J Hum Genet 14(1):17-25

\section{Submit your manuscript to a SpringerOpen ${ }^{\circ}$ journal and benefit from:}

- Convenient online submission

- Rigorous peer review

- Immediate publication on acceptance

- Open access: articles freely available online

High visibility within the field

Retaining the copyright to your article

Submit your next manuscript at springeropen.com 